\title{
A Critical Review of Digital Terrestrial Television Broadcasting in Nigeria
}

\author{
B.I. Bakare and Akujobi Ekeocha
}

\begin{abstract}
The digitization of analog broadcasting signal has brought a significant change in the broadcasting environment today. This means introducing a new way to transmit content, a new and improved mechanism that will provide better reception and increase user satisfaction. This work has taken into account the technical aspect of concerned with digital terrestrial broadcasting, it's evolution, prospects and challenges in Nigeria. Findings show that the future is bright if the challenges such as power, government policies are addressed. Government participation and proper policy management are also key to sustaining the digitization process.
\end{abstract}

Index Terms-Analog; Broadcasting; Digital; Policy Management; Terrestrial

\section{INTRODUCTION}

The deployment of Digital technology in broadcasting has transformed and revolutionized the traditional approach to broadcasting [1]. It has been responsible for the ongoing transition from analogue to digital technology which has transformed the conventional (radio, television and film) mass media as computers and telecommunications are converging to create exciting new media forms [2].

Digital terrestrial television broadcasting is a technique whose technology is based on the transmission of audiovisual media information by bit streams. Digital television is presently an integral part of the information superhighway developed to deliver large amounts of information at very low cost compared to analogue technology and can be fully integrated into completely digital transmission networks [3]..

Digital television has the potential to deliver more programs than traditional analog television over one transmission channel. Broadcasting system that can transmit images with 720 to 1080 horizontal lines of resolution as compared with 480 lines of the ordinary (analog) television system. Also offers interfere free signals.

Fig 1 shows a view of analogue and digital broadcasting. Over the last two decades several types of digital terrestrial broadcasting systems have been developed. Though they might target at different services, they exhibit similarities in some technical features. Usually, multi-carrier technology is employed and psycho-acoustic or psycho-visual effects are exploited to reduce significantly the amount of data to be transmitted in order to maintain the audio or video signals quality to a certain threshold.. Furthermore, the transmission is protected against perturbation by the application of sophisticated error protection mechanisms [4]. Acquiring

B. I .Bakare is with the Department of Electrical Engineering, Rivers State University, Port Harcourt, Nigeria (e-mail: bakare.bodunrin@ust.edu.ng ) setup boxes, with or without monthly subscription will enable viewers receive signals. This reiterates that there exists two broadcasting packages on the terrestrial platform: Free to air and pay TV. The free to air channels can be received without subscription fee, while for the pay TV subscription fee is required to enable viewing.

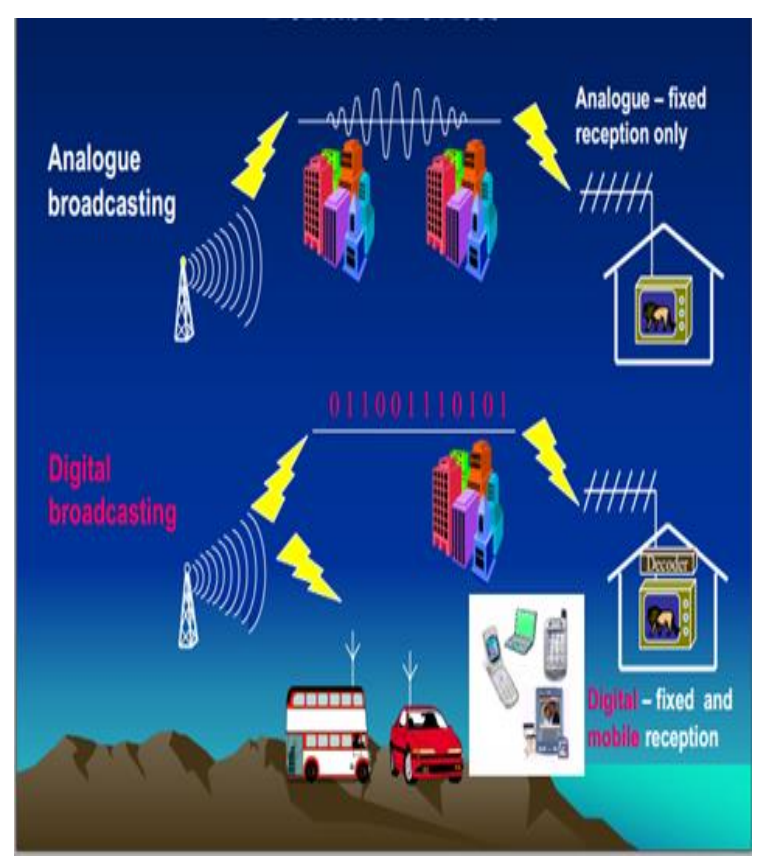

Fig. 1. View of analogue and digital broadcasting [5]

Digital Terrestrial Television (DTT) is received either by means of a computerized set-top box (STB) or coordinated tuner included with TV sets, which interprets the sign got by means of a standard TV reception apparatus as shown in fig.2 Some set-top-boxes incorporate digital video recorder (DVR) usefulness. Be that as it may, because of recurrence arranging issues, an elevated equipped for accepting an alternate channel bunch (more often than not a wideband) may be required if the DTT multiplexes lie outside the gathering abilities of the initially introduced flying. Indoor aerials are much more prone to be influenced by these issues and conceivably need supplanting [6].

Akujobi Ekeocha is with the Department of Computer Science, University of Port Harcourt, Nigeria (e-mail: akujobi.ekeocha@uniport.edu.ng ). 


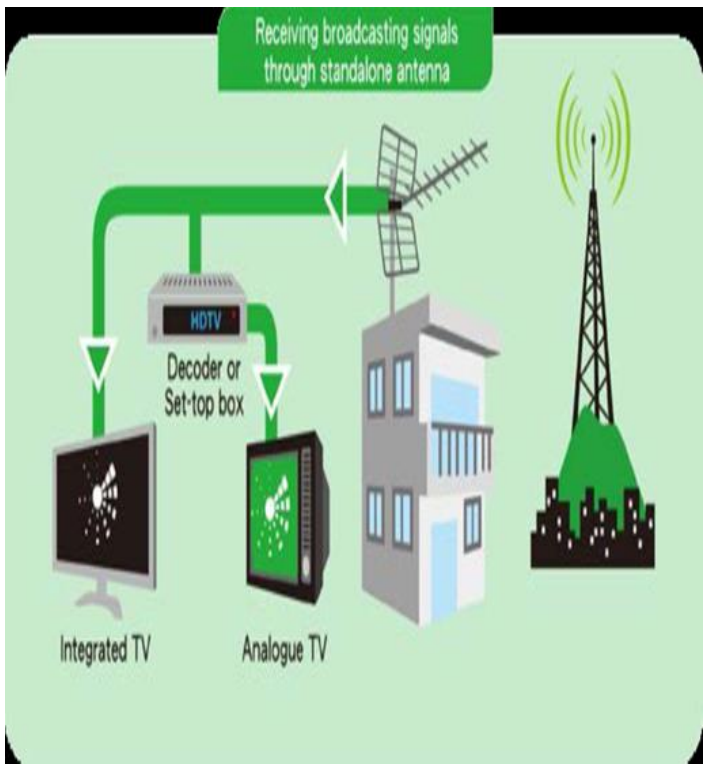

Fig. 2. Reception of DTT signals [6]

\section{EVOlution OF Digital TERRESTRIAL BROADCASTING IN NIGERIA}

At the International Telecommunications Union (ITU) conference in Senegal in 2004 and Geneva in 2006, a unanimous agreement to transit to digital broadcasting was reached and 2015 was set as the deadline date for analog to digital broadcasting transition. A committee was set by The Nigerian Government in 2009 which led to the beginning of digital application in Nigeria [7]. Also, they advocated for upgrade of transmission equipment in the Nigerian Television Authority (NTA) which led to federal government funding the exercise. Meanwhile, Voice of Nigeria (VON) and African Independent Television (AIT) had commenced digital transmission adoption, while Federal Radio Corporation of Nigeria (FRCN) had started the process of digitization as well as other state-owned and private radio stations [8]. This entire plan, was hatched on 17 June 2015and has become an important process for countries to migrate from analogue to digital. In 2016, Nigeria launched the pilot phase of federal governments' digital transmission project transited from analogue to digital.

The NTA-Star TV Network, with the working name "Startimes" is a joint endeavor between the Nigerian Television Authority (NTA) and Beijing Star group. It is a key partnership between the biggest Television Network in Africa (NTA), and China's most powerful radio TV endeavor. Startimes utilizes DVB-T2 as the national standard for Terrestrial Digital Television Broadcasts (DTT),MPEG-4 AVC/264 as standard compression position for digital physical TV and Technology Neutral Mobile TV Standard for Portable TV as shown in Fig 3 below.[10]. The prominent Private DTT Station operating in Nigeria is Go - TV owned by a South Africa Firm, Multichoice (Nig) Ltd.

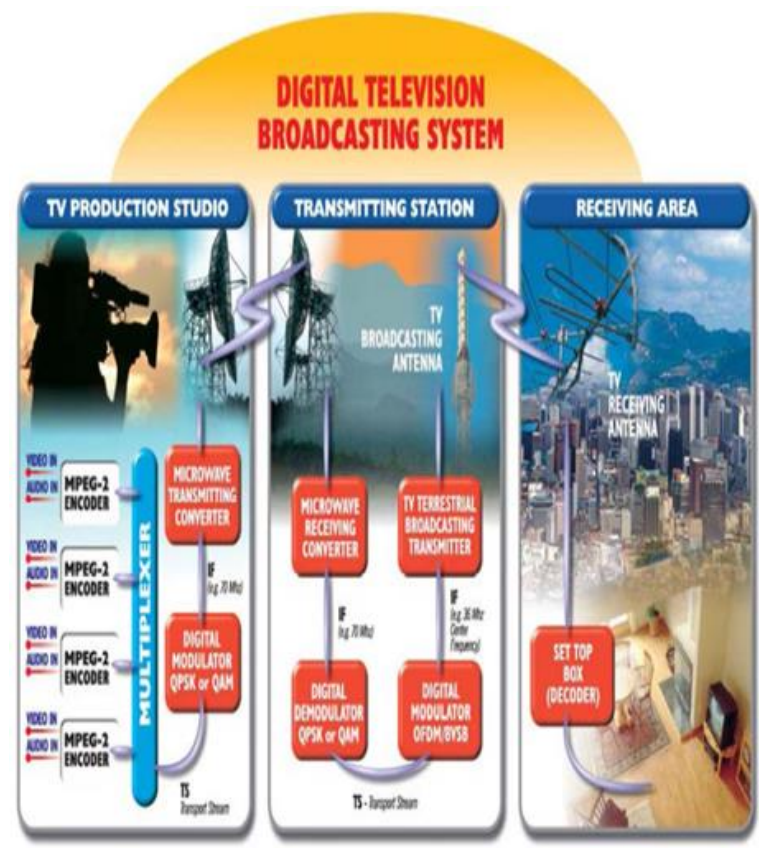

Fig. 3.Structure of the Digital Broadcast System in NTA Using Startimes

\section{DIGITAL TERRESTRIAL TELEVISION SYETEMS}

The Digital Terrestrial Television (DTT) standards allows flexibility which entails that broadcasting planners can adjust their networks by implementing the most appropriate variant among the different possible modes of operation. DTTB will be compatible with the existing 6,7,8 $\mathrm{MHz}$ TV channels and the choice of broadcasting system will depend on certain conditions such as spectrum availability, coverage requirements, structure of existing network, reception conditions. Different DTT systems can operate in different frequency bands. A number of digital terrestrial broadcasting systems for the distribution of television services:

\section{A. Digital Video Broadcasting $(D V B-T),(D V B-H)$ and $(D V B-S H)$}

Digital video broadcasting (DVB-T) was developed by several international organizations like the European Telecommunications Standards Institute (ETSI), DVB-T design will allow reception of television content for portable and mobile receiving conditions. Portable can refer to both indoor and outdoor portable reception. This technology offers subscribers more channels options, up to $70+$ channels.Fig. 4 shows the Architecture of DVB-T2 system

These systems provide end-to-end broadcast for delivery of different types of digital content and services adopting IPbased mechanisms optimized for devices with limitations on computational resources and battery. They consist of a unidirectional broadcast path that may be combined with a bidirectional mobile cellular $(2 \mathrm{G} / 3 \mathrm{G})$ interactivity path. The broadcast path of DVB-SH system uses combined or integrated satellite and terrestrial networks 


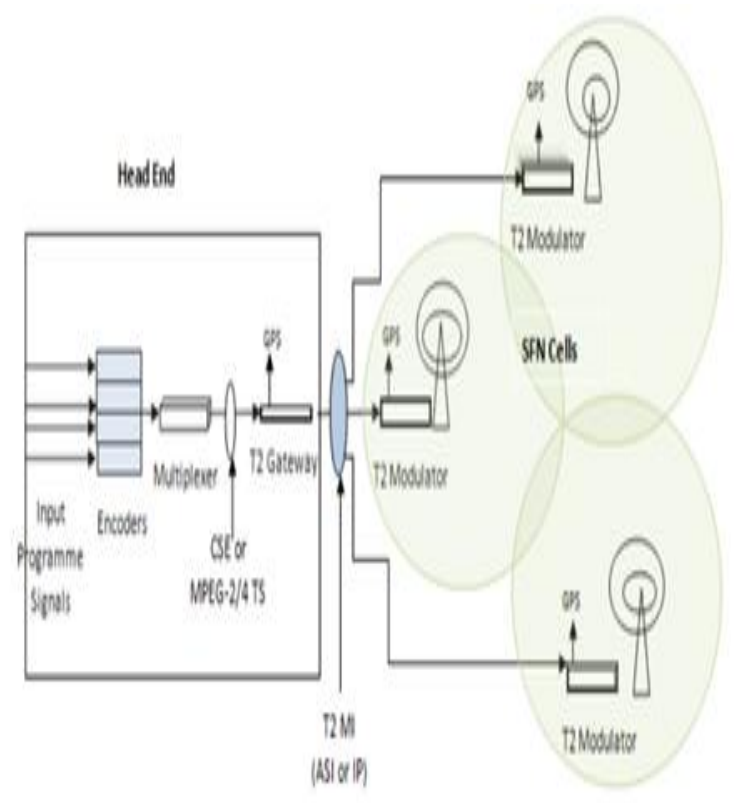

Fig. 4. DVB-T2 Architecture [3]

\section{B. Advanced Television System Committee (ATSC8)}

The ATSC standards are a set of standards developed by the Advanced Television Systems Committee for digital television transmission over terrestrial, cable, and satellite networks. An enhancement of ATSC is the ATSC Mobile which provides multimedia services including video, audio, and interactive data service delivery to small (power efficient) receivers, for fixed, handheld and vehicular environments.

\section{Digital Terrestrial Multimedia Broadcast (DTMB)}

DTMB (Digital Terrestrial Multimedia Broadcast) is a TV standard for mobile and fixed terminals. DTMB system finds compatibility with fixed reception (indoor and outdoor) and mobile digital terrestrial television. Mobile reception is compatible with standard definition digital TV broadcasting, digital audio broadcasting, multimedia broadcasting and data broadcasting service. Fixed reception in addition to the previous services also supports high definition digital TV broadcasting.

\section{REQUIREMENTS FOR DIGITAL TERRESTRIAL TELEVISION}

The following are the stated requirements for digital terrestrial broadcast as stated by ITU [9].

\section{A. The Spectrum Requirements}

- $\quad$ Spectrum usage mode (MFN or SFN)

- $\quad$ Target frequency bands (Band III, IV, V) and extent of spectrum needed to implement the DTTB networks that meet all the requirements above.

\section{B. Receiver equipment Requirements}

- Minimum technical specifications to be able to receive the DTTB programmes (sensitivity, selectivity, operational frequency range, etc.).

- Connectivity characteristics and possible power supply to the active antenna through the feeder

- Middleware for adopted hybrid broadcast broadband system.

- Conditional Access capabilities.

\section{User and Service Requirements}

- $\quad$ Picture quality (SD, HD, UHD, etc.)

- Audio quality (Number of Audio channels.)

- Type and number of Additional services (EPG, Access services)

- Reception mode (fixed, portable, mobile)

- Number of programmes (Video + Audio and associated data)

- Target area/population coverage (percentage of the national area or population, possible obligation in terms of public service mission or national security)

\section{PROSPECTS OF DIGITAL TERRESTRIAL TELEVISION BROADCASTING}

Through the deployment Digital Terrestrial television broadcasting in Nigeria, there are enormous benefits to be achieved. They are as listed as follows:

1. More employment opportunities: This will create opportunities for different categories of persons within the society. Also, enhance the technical expertise of the employed.

2. Efficient utilization of available spectrum: This will allow more channels to be carried across fewer airwaves, thus bringing more choice to the viewer. Digitization permits the broadcasting of four to six more television channels from only one in the current analogue system.

3. Higher quality video and audio: An improved audio and picture quality (1080 lines vertical and 1920 pixels horizontal) will be offered. Aspect ratio of 16:9 widescreen. Audio quality

4. Increased business investment: There will be an increased number of Industries for the manufacture of setup boxes.

5. Increased revenue generation: The establishment of more broadcast stations will lead to a hike in revenue generation from taxes.

\section{CHALLENGES OF DIGITAL TERRESTRIAL TELEVISION BROADCASTING}

There are also challenges which could limit the effective operations of the digital terrestrial television broadcasting in Nigeria as listed:

1. Inadequate power supply: Epileptic power supply in the country will result to the use of power generators which will increase operational cost. 
2. Technical requirement: Huge investment will be required to train personnel in various areas such as hardware installation, software configuration.

3. Low awareness: The concentration of digitization is in the urban area, the rural areas have low awareness of the technology

4. Poverty: The living condition of most families will not encourage this process in terms of purchase of equipment to support viewing.

5. Policies: inconsistency in government policies has greatly hampered the transition from analogue to digital broadcasting.

\section{CONCLUSION}

It is pertinent to note that the deployment of digital TV holds a lot of promise for Nigeria and has the potential to contribute to her economic, socio and technological development. With improved features, DTTB offers better services compared to the existing analog broadcasting. Though there are numerous positives from the deployment of DTTB, its challenges also pose a threat to its operations. Furthermore, the federal government needs to adequately solve the power problems in the country and also provide funding for the digitization process.

\section{REFERENCES}

[1] Okorie Moses, (2010). "The Application of Digital Technology inTerrsetrial Broadcasting" www.edu.ng

[2] Adamu, L. S (2009). "The role of convergence journalism in news production". Paper presented at the school of media and communication, pan-African University; Lagos Conference on Journalism and New Media Technologies, New practices and Renewal of Media Training in Africa. 23rd-27th August edition.

[3] Siaw Ntow Jerry, “A Proposed Implementation Of Digital Terrestrial Television (Dtt) Case Study: Ashanti Region-Ghana" (2013). A thesis submitted to Kwame Nkrumah University of Science and Technology.

[4] Beutler R, The Digital Dividend of Terrestrial Broadcasting, DOI 10.1007/978-1-4614-1569-5 2, Springer Science Business Media, LLC 2012.

[5] An Introduction to Digital Terrestrial Broadcasting (DTT), (2004).

[6] Microsoft Corporation. (2008): Television: First digital broadcasts are transmitted. Microsoft Encarta Encyclopedia: Microsoft Corporation.

[7] Dunu, I. and Ukwueze, C. (2009). "Student awareness and knowledge of digitalization of broadcasting in Nigeria. Implications for Journalism Curriculum". A paper presented at Pan-African University Conference, Lagos. August edition. The Directorate of Engineering and Technology.

[8] Jijiwa, A. (2006). Digital broadcasting and advertising: The Challenges. A paper presented at the advertising practitioners Council of Nigeria Public Forum, Lagos, July 4, 2006.

[9] Handbook on Digital Terrestrial Television Broadcasting Networks and Systems Implementati (2016) ITU-R.

[10] Dominick, J. R. (2009). The Dynamics of Mass Communication: Media in the Digital Age. New York: McGraw Hill.

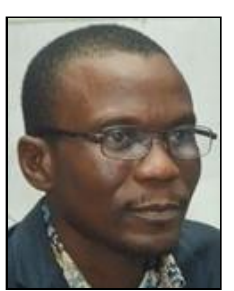

B. I. Bakare holds a Bachelor of Engineering (B.Eng.) Degree in Electrical Engineering; $\mathbf{2}^{\mathbf{1}}$ from Ondo State University, Ado Ekiti, ( Now University of Ado Ekiti, Ekiti State), Master of Engineering (M.Eng.) Degree in Electrical/Electronic Engineering from University of Port Harcourt, Nigeria and he is currently a $\mathrm{PhD}$ (Communication Engineering) Researcher of Nnamdi Azikiwe University (Unizik), Awka, Anambra State. He holds a Category One Wiring License. He is a COREN registered Engineer, a Corporate Member of Nigeria Society of Engineers (NSE), a member of International Association of Engineers (I A ENG) and an active member of Nigeria Institute of Electrical and Electronics Engineers (NIEEE). He is presently a lecturer in the Department of Electrical Engineering, Rivers State University, Port Harcourt., Nigeria

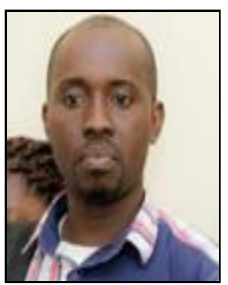

Akujobi Ekeocha holds a Bachelor of Engineering (B.Eng) in Electrical Electronic Engineering from the University of Port Harcourt, Nigeria. He is currently pursuing Postgraduate studies (M.Eng) in Communication Engineering at River State University. $\mathrm{He}$ is a member of International Association of Engineers and Associate Member Institute of Science Laboratory Technologists (AISLT) Nigeria. 